\title{
Corrosion Resistant Plates for Pipes Operated in Sour Environments
}

\author{
Maxim Yu. Matrosov ${ }^{1, a *}$, Oleg. N. Sychev ${ }^{2, b}$,Andrey. M. Korchagin ${ }^{2, c}$, \\ Oleg. P. Talanov ${ }^{1, a}$ \\ ${ }^{1}$ Federal State Unitary Enterprise (FSUE) I. P. Bardin Central Research Institute for Ferrous \\ Metallurgy, Russian Federation, 105005, Moscow, Radio Street 23/9, build. 2 \\ ${ }^{2}$ Public Joint Stock Company (PJSC) Severstal, Russian Federation, 162608, Vologda region, \\ Cherepovets, Mira Street 30 \\ apscenter@chermet.net, ${ }^{\mathrm{b}}$ onsychev@severstal.com, 'amkorchagin@severstal.com
}

Keywords: Sour service steel, corrosion resistance, hydrogen induced cracking, sulfur stress corrosion cracking

\begin{abstract}
Based on physical metallurgy principles, specialists of Severstal and I. P. Bardin Institute developed chemical composition and manufacture technology for microalloyed steel plates for sour service line pipeswith minimum guaranteed tensile strength $510 \mathrm{MPa}$, produced by TMCP (thermomechanical controlled process). The key elements of newly developed technology were: lowcarbon, low-manganese chemical composition with balanced microalloying; production of clean steel in melting shop; microstructure control during all stages of manufacture process.
\end{abstract}

\section{Introduction}

Sour raw hydrocarbons of major oil and gas provinces, both in Russia and globally, require special conditions for transportation and processing. One of the challenging issues is the improvement of corrosion resistance of the pipelines, transporting sour gas. For steels, working in sour environment, manufacturers have to provide not only required set of mechanical properties but also the additional requirements to resistance to HIC (hydrogen induced cracking) [1] and/in some cases, to SSCC (sulfur stress corrosion cracking) [2]. The mechanism of HIC occurrence in structural steels is thoroughly studied (for example, in papers [3,4]), and, briefly, is the result of hydrogen atoms penetration into steel from the environment and recombination of hydrogen to molecular form $\left(\mathrm{H}_{2}\right)$ on structural in homogeneities or inclusions, which, in case of high partial pressure, can result in cracking. HIC occurs without application of external load. Prerequisites for prevention of HIC are also well known [5-7]: decrease of carbon, manganese, sulfur and phosphorus contents in steel to decrease the segregation level and the number of non-metallic inclusions; clean steel production in meting shop ( $\mathrm{S}<0.001 \%, \mathrm{P}<0.006 \%)$, calcium or rare earth elements treatment for modification of inclusion shape; prevention of centerline segregation in continuous cast slabs; control of microstructure in order to avoid banding, etc. In modern clean lowsulfur steels microalloying elements $(\mathrm{Nb}, \mathrm{Ti})$, highly susceptible to segregation, in case of precipitation of large particles of carbonitrides in the slab centerline zone, can be the reason of hydrogen cracks (Fig.1).

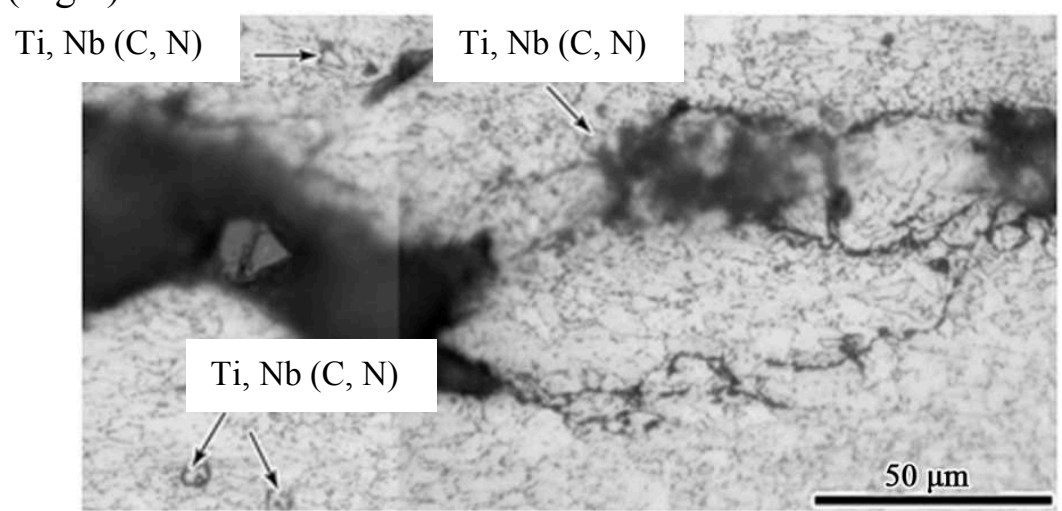

Figure 1. Hydrogen cracks in vicinity of $\mathrm{Ti}, \mathrm{Nb}(\mathrm{C}, \mathrm{N})$ particles in $\mathrm{X} 65$ steel (panoramic view), $3 \%$ $\mathrm{HNO}_{3}$ etching, $\times 400$ 
The appearance of SSCC as delayed brittle fracture is the result of combined effect of corrosion in aqueous H-containing media and tensile stresses [2]. The mechanism of SSCC is considered to be as follows: hydrogen, appearing on the surface of steel, is adsorbed and captured by certain microstructure configurations, resulting in embrittlement of steel and failure under loads lower, than initial yield strength. External factors, affecting the resistance to SSCC are: $\mathrm{H}_{2} \mathrm{~S}$ and $\mathrm{CO}_{2}$ concentration in media, partial pressure, $\mathrm{pH}$ value, time, temperature, tensile stress. Internal factors are following: steel chemical composition, number and shape of non-metallic inclusions, microstructure of steel, strength properties [3, 4, 9-13]. Microstructure control is critically important for SSCC resistance, because crack propagation easily occurs along embrittled ferrite grain boundaries (Fig. 2).

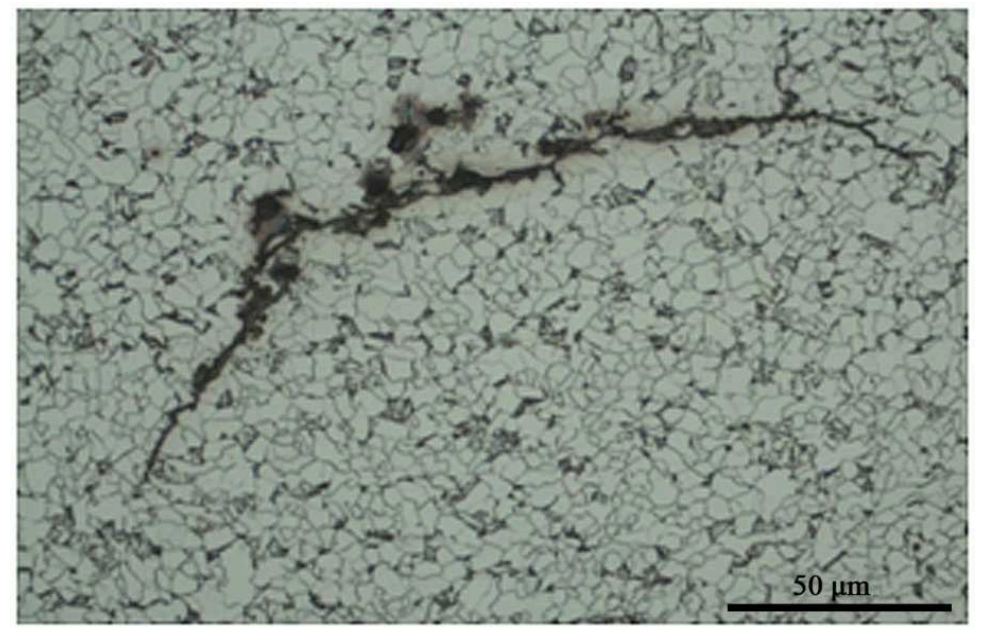

Figure 2. SSCC cracks in ferrite-bainite microstructure of X65 steel, $3 \% \mathrm{HNO}_{3}$ etching, $\times 250$

Producers of steels for sour service report excellent resistance of recently developed steels to HIC $[5,8]$, but, to provide high resistance to SSCC still can be problematic, especially, when testing according to NACE in solution A (Solution A shall consist of $5.0 \mathrm{wt} \% \mathrm{NaCl}$ and $0.5 \mathrm{wt} \%$ glacial acetic acid dissolved in distilled or deionized water), method A (tensile specimens) is required [2].

Taking into the account the concepts of fracture processes in hydrogen sulfide media [1-3], the authors applied the following principles when developing pipe steel resistant both to HIC and SSCC: limitation of content of elements with high tendency to segregation and/or participating in the generation of plastic non-metallic inclusions $(\mathrm{MnS})$; liquid steel treatment with calcium for inclusions shape modification; titanium microalloying in quantity less than stoichiometrical ratio to nitrogen at minimum concentration of the latter for preventing the formation of large particles of titanium nitride in centerline zone of the slab, reduced niobium microalloying to prevent formation of large conglomerates of $\mathrm{Nb}(\mathrm{CN})$ or $\mathrm{TiNb}(\mathrm{CN})$ in centerline zone (Fig. 3); measures for prevention of centerline segregation in slab (Fig.4); microstructure control for maximum grain refinement and obtaining in the microstructure maximum share of bainitic transformation products after accelerated cooling.
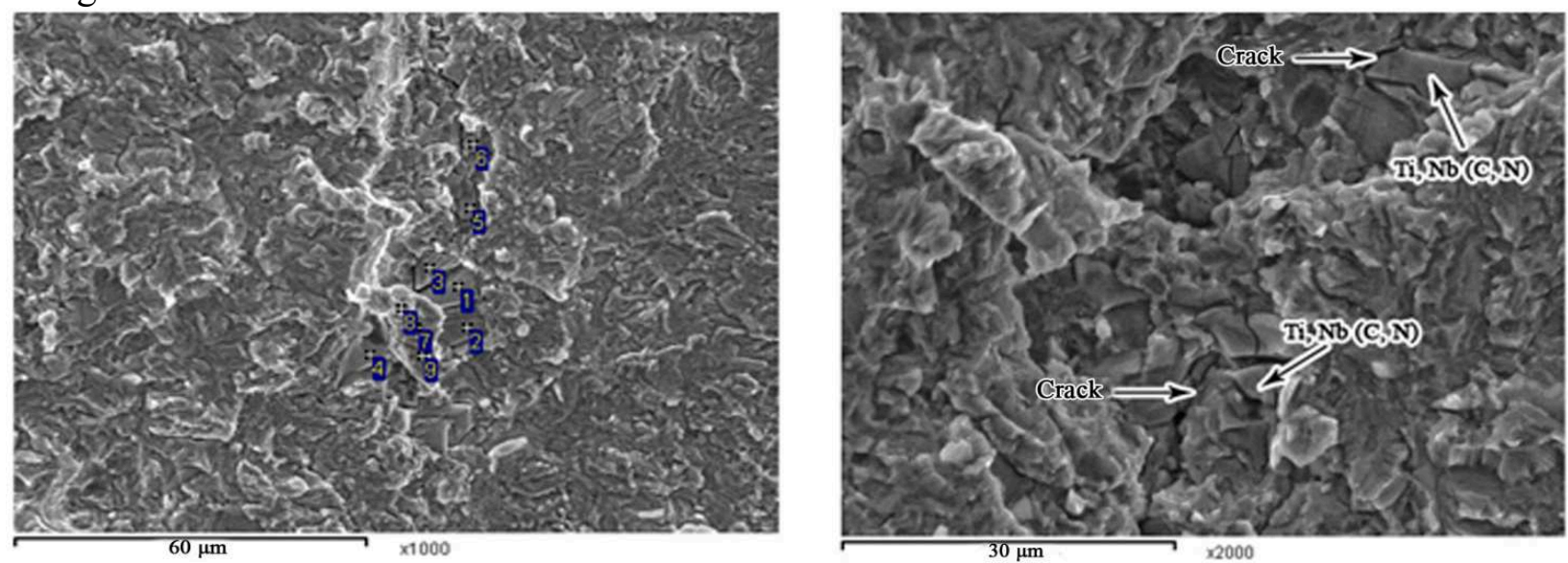

Figure 3. Propagation hydrogen crack around to concentrations of complex particles $\mathrm{Ti}, \mathrm{Nb}(\mathrm{C}, \mathrm{N})$ 


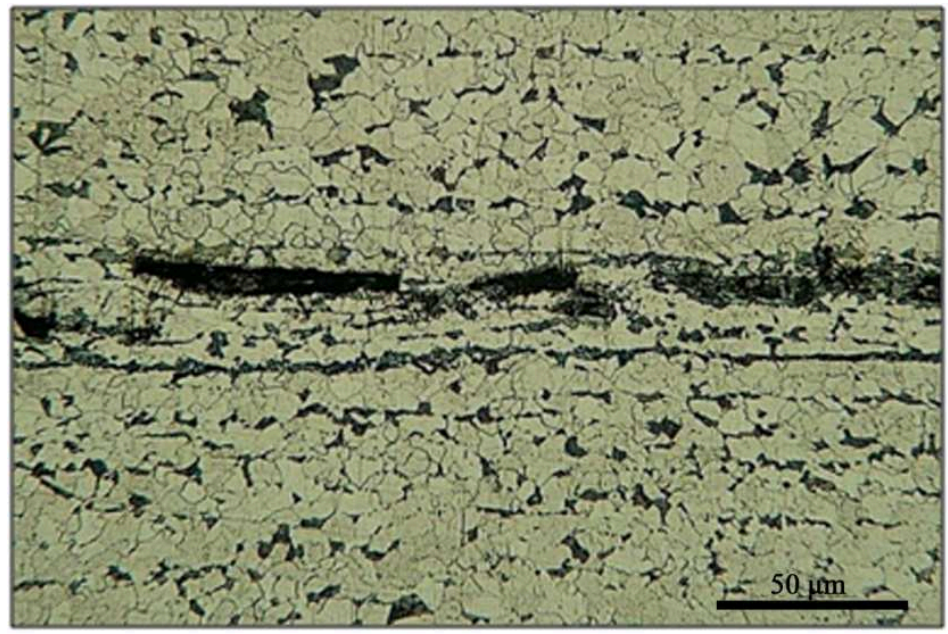

Figure 4. Propagation hydrogen crack in centerline segregation zone steel grade X60

\section{Experimental}

Pilot melting of new sour service steel was performed in Severstal oxygen converter shop. After secondary metallurgy the steel was cast at continuous casting machine (mould section: $250 \times 1625 \mathrm{~mm}$ ) at an average speed of $0.7 \mathrm{~m} / \mathrm{min}$. The slabs were cooled down in pile. Approximate chemical composition of the test heat is shown in Table 1.

Table 1. Approximate chemical composition of test heat (mass fractions of elements [\%])

\begin{tabular}{|c|c|c|c|c|c|c|c|c|}
\hline $\mathrm{C}$ & $\mathrm{Si}$ & $\mathrm{Mn}$ & $\mathrm{P}$ & $\mathrm{S}$ & $\mathrm{Ca} / \mathrm{Al}$ & $\mathrm{Ca} / \mathrm{S}$ & $\mathrm{Cr}+\mathrm{Ni}+\mathrm{Cu}$ & $\mathrm{Nb}+\mathrm{Ti}$ \\
\hline 0.05 & 0.23 & 0.94 & 0.008 & 0.001 & 0.07 & 2.0 & 0.27 & 0.037 \\
\hline
\end{tabular}

Rolling was conducted at Mill 5000 to 12-, 16- and 21-mm thick plates. Thermo-mechanical control process (TMCP) with accelerated controlled cooling (ACC) was selected for the plate production. Rolling schedules were developed to provide the formation of target microstructure of fine grain mixture of massive ferrite and low-carbon bainite without pearlite or bainite bands. The reheating temperature was chosen high enough to provide full dissolution of large $\mathrm{NbCN}$ particles, precipitated during slabs solidification mostly in centerline zone. Large deformations in the first stage of rolling were aimed at maximum austenite grain refinement by multiple recrystallizations. The critical requirement to the second stage of rolling was to provide the rolling finish temperature $30-50{ }^{\circ} \mathrm{C}$ higher $\mathrm{Ar}_{3}(\gamma \rightarrow \alpha$ transformation start temperature) to ensure ACC start temperature higher than $\mathrm{Ar}_{3}$ temperature to avoid structural banding. Accelerated cooling was performed with an average speed of $25^{\circ} \mathrm{C} / \mathrm{s}$ to the temperature range of bainitic transformation to provide the target microstructure formation. After that the plates were stockpiled for retarded cooling for hydrogen removal.

Mechanical tests were conducted using standard methods. For tensile tests flat transversal samples were used universal testing machine Z1500 by Zwick GmbH \& Co, for impact tests Charpy specimens were used pendulum impact tester RKP 450, for drop weight tear tests (DWTT) pressed notch samples were used, tests were conducted on drop weight tear testing machine (impact energy $30000 \mathrm{~J})$.

HIC testing were conducted in test solution A as per NACE TM 0284; initial pH of the solution was 3.30, final - 3.81. Time of one sample testing was $96 \mathrm{hrs}$. SSCC tests were conducted in certified laboratory using method A as per NACE TM 0177 (pre-loaded tensile specimens at threshold stress 0.8 of the specified yield strength in test solution A; test duration: $720 \mathrm{hrs}$.). 


\section{Results and Discussion}

Mechanical properties of plates, manufactured from the trial heat fully meet the requirements of specification: yield point no less than $370 \mathrm{MPa}$, tensile strength within the range of 510 to $620 \mathrm{MPa}$, yield ratio not exceeding 0.88 , elongation no less than $22 \%$ (see Table 2). Average hardness level was around $180 \mathrm{HV}$.

Table 2. Mechanical properties of plates from pilot batch

\begin{tabular}{|c|c|c|c|c|c|}
\hline $\begin{array}{c}\text { Yield strength } \\
{[\mathrm{MPa}]}\end{array}$ & $\begin{array}{c}\text { Tensile } \\
\text { strength }[\mathrm{MPa}]\end{array}$ & Ratio & Elongation $[\%]$ & $\begin{array}{c}\mathrm{KCV}^{-40} \\
{\left[\mathrm{~J}^{2} \mathrm{~cm}^{2}\right]}\end{array}$ & $\begin{array}{c}\text { DWTT } \\
{[\%]}\end{array}$ \\
\hline $450 \pm 20$ & $530 \pm 20$ & $0.84 \pm 0.03$ & $23 \pm 1$ & $385 \pm 40$ & 100 \\
\hline
\end{tabular}

HIC tests according to NACE TM 0284 [1] satisfied the requirements for each section, three different cracking parameters were measured according to Equations. The HIC susceptibility values of CLR, CTR, and CSR for each sample were the average of three section results:

Crack Length Ratio: CLR $=\frac{\sum \mathrm{a}}{\mathrm{W}} \mathrm{X} 100 \%$

Crack Thickness Ratio: CTR $=\frac{\sum \mathrm{b}}{\mathrm{T}} \mathrm{X} 100 \%$

Crack Sensitivity Ratio: $\mathrm{CSR}=\frac{\sum(\mathrm{axb})}{\mathrm{WXT}} \mathrm{X} 100 \%$

where ' $a$ ' is the crack length in $\mathrm{mm}$; ' $b$ ' the crack thickness in $\mathrm{mm}$; ' $\mathrm{W}$ ' the section width in mm; and ' $\mathrm{T}$ ' the test specimen thickness in $\mathrm{mm}$.

SSCC tests according to NACE TM 0177 in test solution A (solution A shall consist of $5.0 \mathrm{wt} \%$ $\mathrm{NaCl}$ and $0.5 \mathrm{wt} \%$ glacial acetic acid dissolved in distilled or deionized water), method A [2] demonstrated excellent resistance of plates from the pilot batch (see Table 3).

Table 3. HIC and SSCC resistance of plates from pilot batch

\begin{tabular}{|c|c|c|c|c|c|c|}
\hline \multirow{3}{*}{$\begin{array}{l}\text { Plate } \\
\text { number }\end{array}$} & \multirow{3}{*}{$\begin{array}{c}\text { Thickness } \\
\text { [mm] }\end{array}$} & \multicolumn{5}{|c|}{ Resistance parameters } \\
\hline & & \multicolumn{3}{|c|}{$\mathrm{HIC}$} & \multicolumn{2}{|l|}{ SSCC } \\
\hline & & $\begin{array}{c}\text { CLR } \\
{[\%]}\end{array}$ & $\begin{array}{l}\text { CTR } \\
{[\%]} \\
\end{array}$ & $\begin{array}{l}\text { CSR } \\
{[\%]} \\
\end{array}$ & $\sigma_{\mathrm{th}}$ in fractions of $\sigma_{\mathrm{T}} \min$ & $\begin{array}{l}\text { Time before } \\
\text { fracture, hours }\end{array}$ \\
\hline 1 & 21 & 0 & 0 & 0 & \multirow{4}{*}{$\begin{array}{l}0.8 \text { of } \sigma_{\mathrm{T}} \min \\
(370 \mathrm{MPa})\end{array}$} & \multirow{4}{*}{$\begin{array}{c}720 \\
\text { no cracks } \\
\text { detected }\end{array}$} \\
\hline 2 & 21 & 0 & 0 & 0 & & \\
\hline 3 & 12 & 0 & 0 & 0 & & \\
\hline 4 & 12 & 0.69 & 0.05 & 0 & & \\
\hline \multicolumn{2}{|c|}{$\begin{array}{l}\text { Normative } \\
\text { documentation } \\
\text { requirements }\end{array}$} & $\leq 3$ & $\rightarrow 0$ & - & 0.8 of $\sigma_{\mathrm{T}} \min$ & $\begin{array}{l}720 \text { hours } \\
\text { without } \\
\text { fracture }\end{array}$ \\
\hline
\end{tabular}

Microstructure of plates from the pilot batch is shown in Figure 5.

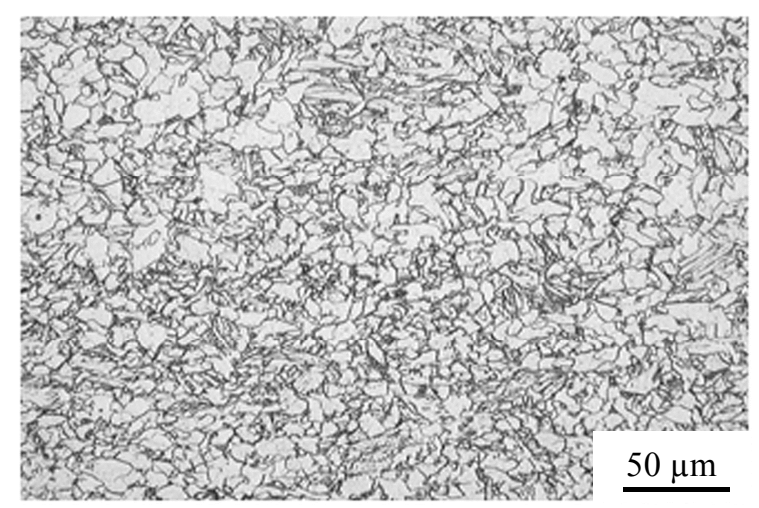

a

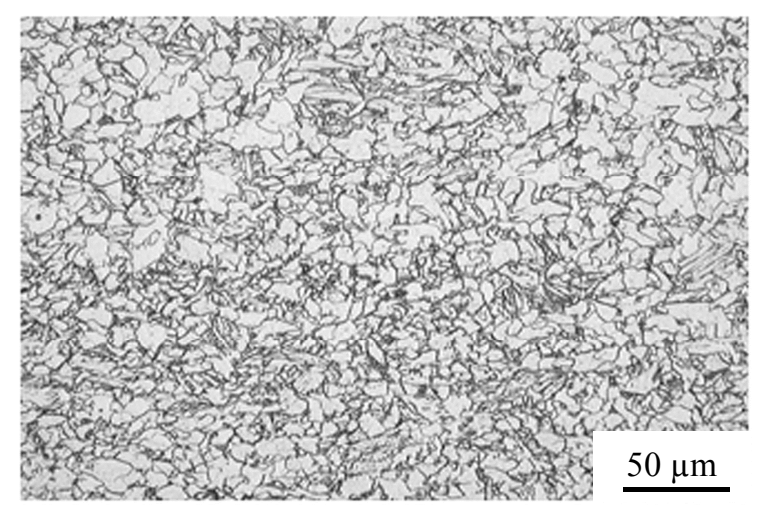

b

Figure 5. Microstructure of pilot batch plate, thickness $12 \mathrm{~mm}, 3 \% \mathrm{HNO}_{3}$ etching, a $-1 / 2$ of thickness, $b-1 / 4$ of thickness 
Developed heating, controlled rolling and accelerated cooling schedules allowed to obtain the refined homogeneous ferrite-bainite microstructure without structural banding both in $1 / 4$ (Fig. 5, a) and $1 / 2$ (Fig. 5, b) section of the plates across the thickness. Size of ferrite grains does not exceed $10 \mu \mathrm{m}$, size of bainitic regions $-50 \mu \mathrm{m}$, no banding. Such a fine and uniform microstructure is the result of severe deformation during austenite conditioning and application of intensive accelerated cooling with ACC start temperature higher than $\mathrm{Ar}_{3}$ temperature.

Examination of microstructure, performed using electron transmission microscopy (TEM), demonstrated, that ferrite matrix consists of a mixture of acicular and polygonal /quasipolygonal ferrite (Fig. 6). Secondary (high carbon) phases are represented by isolated islands of upper bainite or degenerated pearlite (Fig. 7).

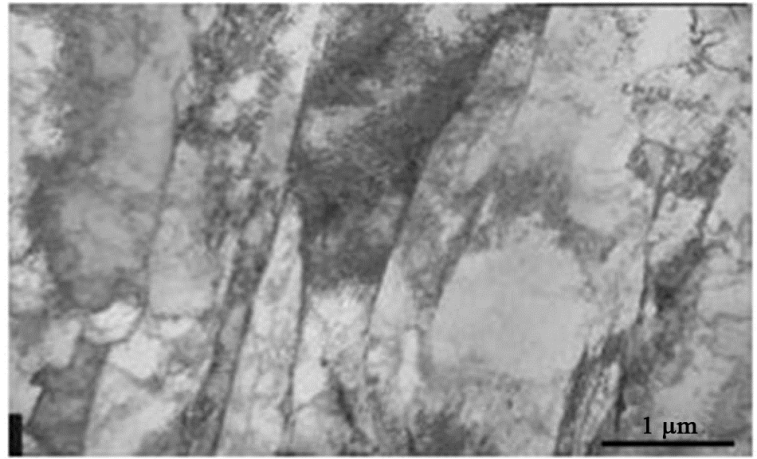

a

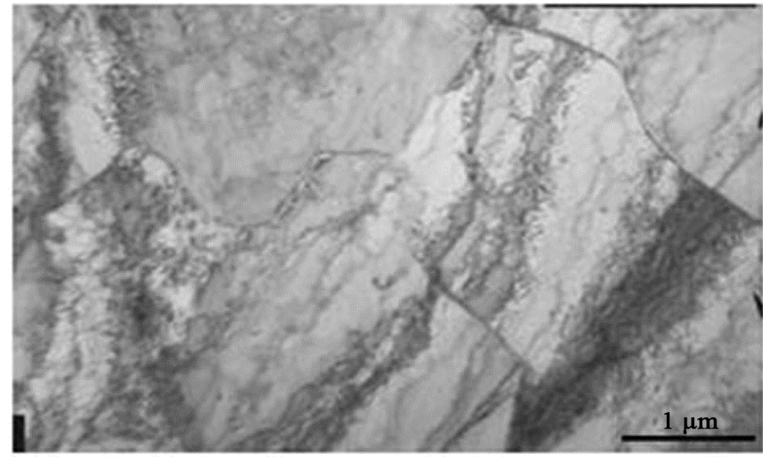

b

Figure 6. Ferritic microstructure of the $12 \mathrm{~mm}$ plate from the pilot batch, TEM, Bright Field, $\times 15000, a$ - lath-like bainitic ferrite, $b$ - quasipolygonal ferrite

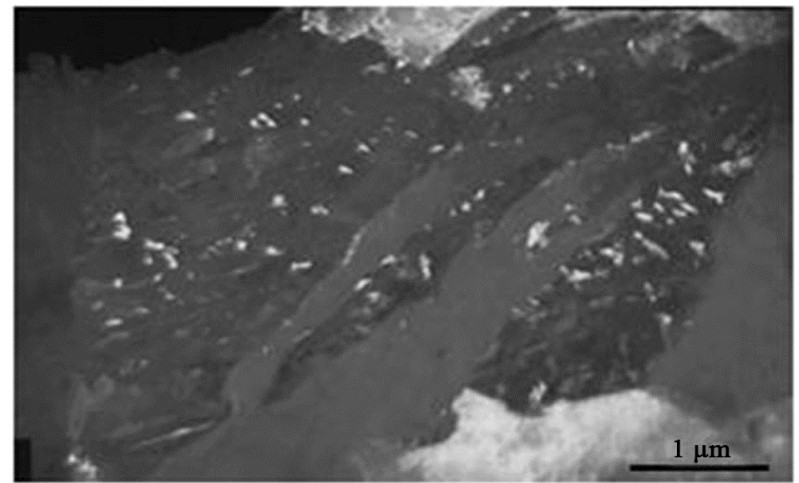

$\mathrm{a}$

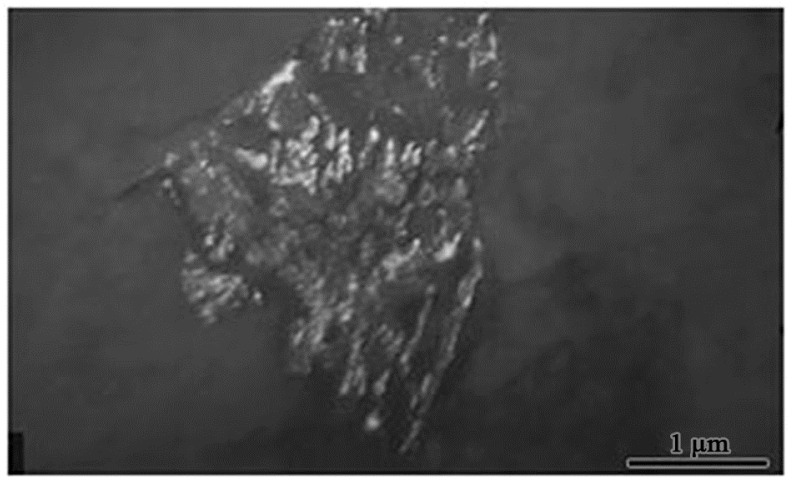

b

Figure 7. High-carbon structures, $12 \mathrm{~mm}$ plate, pilot batch, TEM, dark field in cementite reflex, $\times 15000$, a - upper bainite, $b$ - degenerated pearlite

Carbonitride precipitates are represented predominantly by medium-sized precipitates, $(40-80 \mathrm{~nm})$, presumably $\mathrm{TiNb}(\mathrm{CN})$ (Fig. 8). No large cubic TiN particles, harmful for HIC and SSCC resistance, were found in the microstructure.

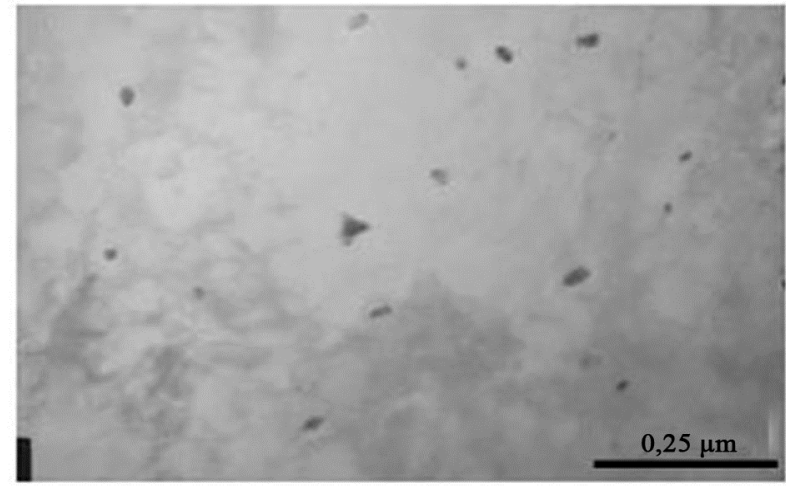

a

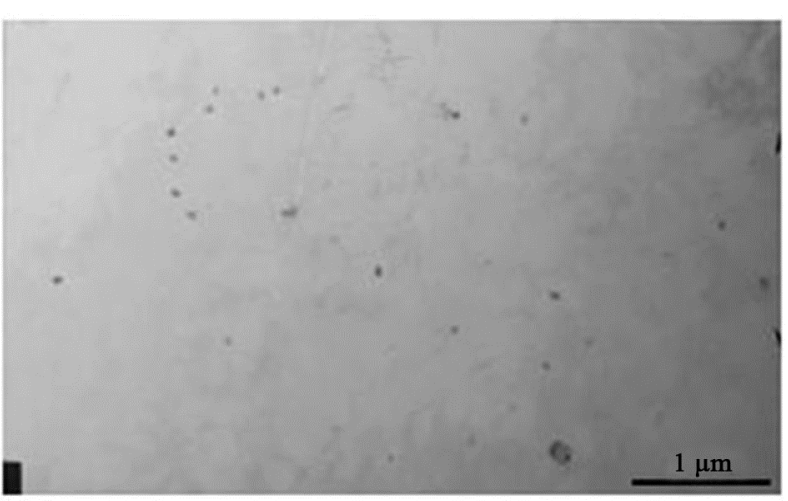

b

Figure 8 . Medium-size precipitates of carbonitrides, TEM, bright field, $a-\times 30000, b-\times 15000$ 
Comparison of results of corrosion tests and microstructure examination allows coming to the conclusion, that unfavorable factors, affecting both HIC and SSCC resistance of steel, were minimized by application of developed production schedules. Clean steel production and inclusion shape control minimized the number of crack initiation sites. Fine and homogenous microstructure without structural banding, formed by severe deformation schedules both in recrystallization and non-recrystallization regions and accelerated cooling from high temperatures to lower part of bainite region, provided higher resistance to crack propagation both in case of HIC and SSCC. The absence of large cubic particles of TiN provided fewer possibilities for micro-cracks formation in the process of severe deformation, which could be the initiation sites for hydrogen cracks. Microstructure, consisting of products of bainite transformation, is more resistant to SSCC because of deformed grain boundaries, without cementite layers, making more difficult crack propagation between microstructural constituents. Minimization of centerline segregation by decreasing of contents of elements such as carbon, sulfur, manganese, and balanced microalloying, allowed to avoid the formation of hard microstructures, responsible for the majority of cracks, occurring in the process of HIC.

\section{Conclusion}

Results of pilot batch production of highly resistant to HIC and SSCC steel demonstrated, that the development of chemical composition of steel technological schedules, aimed at the production of clean steel, with controlled microstructure allowed to provide not only the required level of mechanical properties, but also excellent resistance both to HIC (NACE TM 0284) and SSCC (NACE TM 0177, method A, solution A).

\section{References}

[1] NACE Standard TM0284-2011 Evaluation of Pipeline and Pressure Vessel Steels for Resistanse to Hidrogen-Induced Cracking, Houston, Texas, 2011.

[2] NACE Standard TM0177-2005. Laboratory Testing of Metals for Resistance to Sulfide Stress Cracking and Stress Corrosion Cracking in $\mathrm{H}_{2} \mathrm{~S}$ Environments. Houston, Texas, 2005.

[3] Nakasugi H., Matsuda H. Development of new line-pipe steels for sour-gas service. - Nippon steel Techn. Rep.1979, №14, p.66-78.

[4] Treseder R., Swanson T. Factors in sulfide corrosion cracking of high strengthsteels. Corrosion, 1968, v.24, №2, p.31-37.

[5] Schröder J., Schwinn V., Liessem A. Recent development of sour service line pipe steels.Europipe, Technical Publications from 2006.

[6] Kalwa C., Hillenbrand H-G. Europipe's experience and developments on pipe materials for sour service applications. Sour Service Seminar, Brazil, SanPaulo, 2012.

[7] Ogibayashi S. en al., Control of Center Segregation in Continuous Cast Slab for Sour Gas Service Line Pipe Steels, $7^{\text {th }}$ Japan-Germany Seminar, Germany, Dusseldorf, 1987, 309.

[8] Ishikawa N., Endo Sh., Muraoka., Kakihara Sh., Kondo J., Material Design of High Strength/Heavy Gauge Linepipes for Sour Service, Sour Service Seminar, Brazil, SanPaulo, 2012.

[9] Townsend H. Hydrogen sulfide stress corrosion cracking of high strength steels wire. Corrosion, 1972, v.28, №2, p.39-46.

[10] Li.J.,Oriani R., Darken L. The thermodynamic of stressed solids. - Zeitschrift fur physic. Chem N.F., 1966, Bd49, № 3-5, p. 271-290.

[11] W. Haumann and O. Koch, 3R international 25 (1986), No.5, p. 261-266.

[12] Niobium Information $N_{0} .18 / 01$, CBMM/NPC, Dusseldorf (Germany), 2001.

[13] M. Iino, N. Nomura, H. Takezawa and T. Takeda, 1st Int. Conf. On Current Solutions for Hydrogen Problems in Steel, Washington (DC), Nov. 1982. 